\title{
Alterações oculares em paciente pediátrico portador de malformações de Dandy-Walker: relato de caso
}

\author{
Ocular alterations in a pediatric patient with Dandy-Walker malformations: case report
}

\author{
Oscar Ewald ${ }^{1}$ \\ Fernanda Scremin ${ }^{2}$ \\ Fábio Busch ${ }^{3}$ \\ Roberto Von Hertwig'
}

Trabalho realizado na Clínica de Olhos Roberto Von Hertwig - Rua Itajaí, 417 - Blumenau (SC) - Brasil.

${ }^{1}$ Acadêmico do curso de Medicina da Universidade Regional de Blumenau - Blumenau (SC) - Brasil.

Médica formada pela Pontifícia Universidade Católica do Paraná - PUCPR - Curitiba (PR) - Brasil.

${ }^{3}$ Fellow em Retina e Vítreo pelo Hospital das Clínicas da Universidade Federal de Goiânia - UFG - Goiânia (GO) - Brasil.

${ }^{4}$ Professor e Coordenador da cadeira de Órgãos dos sentidos - Oftalmologia - Universidade Regional de Blumenau - FURB - Blumenau (SC) - Brasil.

Endereço para correspondência: Oscar Ewald

Rua Procópio Domingos Alexandre, 90

Blumenau (SC) CEP 89037-360

E-mail: oscarewald@pop.com.br f.scremin@uol.com.br

Recebido para publicação em 04.05.2005

Versão revisada recebida em 04.10.2005

Aprovação em 29.10.2005

Nota Editorial: Depois de concluída a análise do artigo sob sigilo editorial e com a anuência da Dra. Simone Finzi sobre a divulgação de seu nome como revisora, agradecemos sua participação neste processo.

\begin{tabular}{|l|}
\hline RESUMO \\
\hline Descreveremos um caso raro de malformações da síndrome de Dandy- \\
Walker e suas alterações oculares. Trata-se de criança do sexo feminino, \\
com idade de 1 ano e 9 meses, que apresentava alterações no sistema \\
nervoso central (síndrome de Dandy-Walker), associado à baixa acui- \\
dade visual, megalocórnea (diâmetro de 13 mm no olho direito e $13,5 \mathrm{~mm}$ \\
no olho esquerdo), escavação de 0,7 em ambos os olhos (AO) e palidez \\
temporal de papila óptica de AO, pressão intra-ocular de 16 mmHg no \\
olho direito e 14 mmHg no olho esquerdo e diâmetro antero-posterior de \\
20,55 mm em ambos os olhos.
\end{tabular}

Descritores: Síndrome de Dandy-Walker; Glaucoma/congênito; Malformações do sistema nervoso; Manifestações oculares; Relatos de casos [tipo de publicação]

\section{INTRODUÇ̃̃̃O}

O relato clássico, feito por Dandy \& Blackfan em 1914*, revelou casos em autópsias com hidrocefalia severa supratentorial, dilatação cística do quarto ventrículo, vermis pequeno, afastamento dos hemisférios cerebelares, ausência do teto do quarto ventrículo, espessamento e opacificação da pia-aracnóide das cisternas da base do crânio e dilatação do aqueduto(1).

A síndrome de Dandy-Walker (SDW) é uma síndrome não familiar, caracterizada por dilatação cística do quarto ventrículo e por aplasia ou hipotrofia parcial ou total do vermis cerebelar. Geralmente apresenta atresia dos forames de Lushka e Magendie. Em três quartos dos casos ocorrem outras malformações cerebrais como agenesia do corpo caloso, heteropsias, lissencefalia, estenose do aqueduto de Sylvius ${ }^{(2-3)}$. Gardner et al** propuseram que a SDW, juntamente com outras síndromes (Arnold-Chiari, cisto aracnóide de cerebelo e siringomielia), seriam manifestações de uma mesma doença $\mathrm{a}^{(1)}$.

Alguns estudos mostram uma incidência de aproximadamente $70 \%$ de relação entre a SDW e anomalias sistêmicas ${ }^{(1)}$.

Pouco se sabe sobre malformações congênitas das estruturas da fossa posterior, suas alterações genéticas foram mapeadas para o cromossomo $3 \mathrm{q}^{(4-5)}$, mas o gene ao certo não localizado, porém sabe-se que a base do processo de desenvolvimento das estruturas da fossa posterior é a natureza para as malformações cerebelares humanas ${ }^{(5)}$. Sabe-se também que as estruturas cerebelares se desenvolvem precocemente no período embrionário até os primeiros anos pós-natais, este acontecimento deixaria o cerebelo vulnerável a um largo espectro de desordens do seu desenvolvimento ${ }^{(6)}$. A

\footnotetext{
* Dandy \& Blackfan apud ${ }^{(1)}$

**Gardner et al. apud ${ }^{(1)}$
} 
patogenia desta síndrome é controvertida, porém a teoria mais aceita é a de que a folha do desenvolvimento dos forames de Lushka e Magendie, durante o quarto mês de vida fetal, leva ao abaulamento cístico do quarto ventrículo. Novas teorias propuseram que a SDW decorreria de uma falha no desenvolvimento no teto do rombencéfalo, tendo este como causa um efeito teratogênico ${ }^{(1)}$. Alguns trabalhos sugerem que o uso de warfarin em longo prazo seria responsável pelo desenvolvimento da SDW em 1-2\% dos fetos expostos ${ }^{(7)}$. O que vem reforçar ainda mais esta teoria é que um estudo realizado por Hart et al., mostrou que não há relação entre grau de hidrocefalia e o tamanho do cisto da fossa posterior, atenuação do vermis ou permeabilidade do quarto ventrículo e em alguns casos a hidrocefalia estava ausente ${ }^{(1)}$. A SDW é uma entidade heterogênica de hipoplasia de vermis cerebelar, sendo recentemente identificado um gene associado à ligação com X-HPRT ${ }^{(8)}$, também relacionado com doença de gânglios da base.

Clinicamente pode haver moderado atraso do desenvolvimento psicomotor, microcefalia, hipotonia, mas a sintomatologia predominante se refere à hidrocefalia, geralmente nos dois primeiros anos de vida, esta porém, pode ser ignorada, aparecendo tardiamente (primeira ou segunda década de vida) ${ }^{(2-9)}$. A hidrocefalia se dá pela obstrução dos forames de Lushka e Mangedie ${ }^{(1)}$. Algumas alterações oculares (Tabela) são descritas na SDW, como: coloboma corioretiniano ${ }^{(10)}$, nistagmo ${ }^{(11-13)}$. Pode haver retardo mental (50\%), espasticidade (ao invés de hipotonia), convulsões, vômitos, tudo dependendo do grau da malformação cerebelar ${ }^{(3)}$. Em pacientes com vermis com duas fissuras e conformações praticamente normais, as funções cerebrais são também praticamente normais sem associações com outras malformações. Já em pacientes com severas malformações do cerebelo, vermis com apenas uma ou nenhuma fissura, é comum o retardo mental severo e outras malformações do sistema nervoso central, como agenesia de corpo caloso. Divide-se, assim, a SDW em dois grandes grupos conforme as malformações anteriores para a determinação do prognóstico intelectual ${ }^{(12-13)}$. São relatados na literatura casos de coexistência de grandes hemangiomas cutâneos faciais com a SDW ${ }^{(14)}$.

Outras síndromes onde coexistem malformações cerebrais e oculares são relatadas como síndrome de Neuhauser (MMMM - Megalocornea, macrocephaly, mental and motor retardation), onde são encontrados atrofia cortical, aumento do quarto ventrículo, hipoplasia do corpo caloso. Tudo isto considerado uma variante da SDW, juntamente com megalocórnea ${ }^{(15)}$. Há também a síndrome de Warburg que, além de malformações cerebrais como o cisto de Dandy-Walker, apresenta microftalmo e megalocórnea ${ }^{(16)}$. Esta última também

Tabela. Alterações oftalmológicas na síndrome de Dandy-Walker
- Coloboma corioretiniano;
- Nistagmo;
- Megalocórnea;
- Microftalmo.

pode ser autossômica dominante ou ligada ao X, bem como associada à síndrome de Marfan. Existem relatos sobre a relação de malformações da fossa posterior com nistagmo, sendo estas chamadas de síndrome cerebelo-oculorenal ${ }^{(11)}$. Outros, sobre síndrome do músculo-olho-cérebro de Santavoure que, além de hidrocefalia, hipotonia, fraqueza, aumento de CPK, há também alta miopia e glaucoma congênito ${ }^{(17)}$. Há também o relato da chamada síndrome PHACE (Posterior fossa malformations, hemangioma, arterial anomalies, coarctation of the aorta and other cardiac defects, and eye abnormalities $)^{(10)}$. Em um estudo entre pacientes com síndrome de Turner, um de seus 23 casos estava presente $\mathrm{SDW}^{(18)}$.

Para o diagnóstico há necessidade da ressonância magnética com imagens de boa qualidade da vista axial do vermis cerebelar e imagens em $\mathrm{T}_{2}^{(12)}$. Os achados neuroradiológicos são característicos, como a dilatação cística do quarto ventrículo e as alterações no vermis cerebelar ${ }^{(2)}$, além de outras já citadas.

A SDW deve sempre ser acompanhada pelo pediatra, neurocirurgião e um fisioterapeuta. Em caso de convulsões, devem ser usados anticonvulsivantes. Nos casos de hipotonia ou espasticidade, a conduta cabe ao fisioterapeuta ${ }^{(3)}$. O tratamento da hidrocefalia sempre será cirúrgico, através de uma derivação ventrículo-peritoneal ${ }^{(2)}$. Esta poderá ser feita por neuroendoscopia, comunicando o cisto do quarto ventrículo com o sistema ventricular, e este com o peritônio ${ }^{(3,19)}$.

\section{RELATO DE CASO}

BSF, 1 ano e 9 meses, sexo feminino, foi referida ao Serviço de Oftalmologia da Clínica de Olhos Roberto Von Hertwig com história de "síndrome de Dandy-Walker" para avaliação oftalmológica (Figura).

Antecedentes pessoais: Mãe relata o não uso de drogas durante a gestação. Não existindo consangüinidade entre os pais. Criança com ressonância magnética compatível com sín-

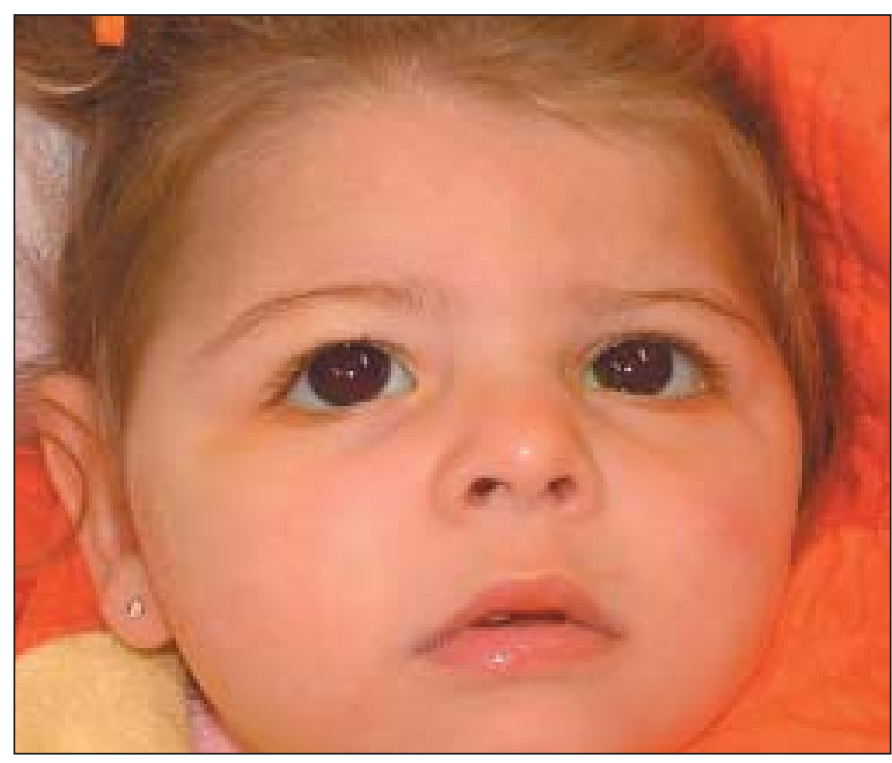

Figura - Megalocórnea e microcefalia 
drome de Dandy-Walker, com volumosa coleção na fossa posterior e com ampla comunicação com o quarto ventrículo, associada com sinais de hipoplasia dos hemisférios cerebelares, do vermis e do tronco cerebelar. Cariótipo não realizado. Mãe relata que a criança tem microcefalia, segundo o pediatra; também apresenta história de nistagmo.

Exame oftalmológico: Criança fixa luz, mas não segue luz nem objetos pequenos. Ortofórica e ortotrópica e ausência de nistagmo. Na biomicroscopia, apresenta megalocórnea, com córnea de $13 \mathrm{~mm}$ no olho direito e 13,5 mm no olho esquerdo. A refração estática sob cicloplegia do olho direito é $+5,00$ dioptrias esféricas (DE) e -3,50 dioptrias cilíndricas (DC) a $180^{\circ}$ e do olho esquerdo é $+5,00 \mathrm{DE}$ e $-4,00 \mathrm{DC}$ a $180^{\circ}$. Fundoscopia com escavação de 0,7 no disco óptico de $\mathrm{AO}$ e palidez temporal dos discos em $\mathrm{AO}$, sendo escavação maior que a palidez. Pressão intra-ocular, sem sedação, de $16 \mathrm{mmHg}$ no olho direito e $14 \mathrm{mmHg}$ no olho esquerdo. Ecobiometria demonstrando diâmetro antero-posterior do olho de 20,55 $\mathrm{mm}$ em ambos os olhos. Sem fotofobia, lacrimejamento ou estrias de Haab (ou outra alteração da córnea).

Foram então prescritas lentes para correção da visão com $+1,50 \mathrm{DE} \approx-1,50 \mathrm{DC}$ a $180^{\circ}$ no olho direito e $+1,50 \mathrm{DE} \approx-2,00 \mathrm{DC}$ a $180^{\circ}$ e encaminhada para estimulação visual.

\section{DISCUSSÃO}

O fato de a paciente ter escavação de 0,7 no disco óptico de $\mathrm{AO}$ com palidez temporal em $\mathrm{AO}$, aliada à existência de megalocórnea, pode sugerir glaucoma congênito.

Porém a paciente é hipermétrope, com diâmetro anteroposterior normal para a idade, pressão intra-ocular, sem sedação, não aumentada, sem fotofobia, lacrimejamento ou estrias de Haab (ou outra alteração da córnea), não sugerindo o diagnóstico de glaucoma congênito.

Existem trabalhos que citam a existência de megalocórnea com malformações neurológicas e variantes da SDW ${ }^{(15-16)}$.

A hipótese diagnóstica mais provável é que, por se tratar de uma síndrome com malformações neurológicas ${ }^{(2-3)}$, esta seja a origem do comprometimento do disco óptico.

Foram prescritas lentes corretoras para que a criança pudesse ser visualmente estimulada, evitando ambliopia.

Outras alterações comuns na síndrome de Dandy-Walker, como coloboma corioretiniano ${ }^{(10)}$ e nistagmo ${ }^{(3,11)}$, não foram encontradas no momento.

Foi dada orientação aos pais para nova avaliação em dois meses.

\section{ABSTRACT}

We describe a rare case of Dandy-Walker syndrome malformation and its ocular alterations. A female child, aged 1 year and
9 month, with central nervous system alterations (DandyWalker syndrome), associated with low visual acuity, megalocornea (13 mm diameter in right eye and $13.5 \mathrm{~mm}$ in the left), fundoscopy with 0.7 optic papilla excavation in both eyes (BE) and temporal paleness in $\mathrm{BE}$, intraocular pressure of $16 \mathrm{mmHg}$ in the right eye and $14 \mathrm{mmHg}$ in the left and anteroposterior diameter of $20.55 \mathrm{~mm}$ in both eyes.

Keywords: Dandy-Walker syndrome; Glaucoma/congenital; Nervous system malformation; Eye manifestations; Case reports [publication type]

\section{REFERÊNCIAS}

1. Diament A. Neurologia infantil 3a ed. São Paulo: Atheneu; 1996.

2. Rosenberg S. Neuropediatria. São Paulo: Sarvier; 1995.

3. Yilmaz MA. The site on Dandy Walker Syndrome [homepage on the Internet]. [cited 2005 Aug 29]. Available from: http://www.geocities.com/murat_ yil/dandy.html

4. Parisi MA, Dobyns WB. Human malformations of the midbrain and hindbrain: review and proposed classification scheme. Mol Genet Metab. 2003; 80(1-2):36-53.

5. Chizhikov V, Millen KJ. Development and malformations of the cerebellum in mice. Mol Genet Metab. 2003;80(1-2):54-65.

6. Ten Donkelaar HJ, Lammens M, Wesseling P, Thijssen HO, Renier WO. Development and developmental disorders of the human cerebellum. J Neurol. 2003;250(9):1025-36.

7. Koren G, Pastuszak A, Ito S. Drugs in pregnancy. N Engl J Med. 1998;338(16): 1128-37.

8. Daufenbach DR, Ruttum MS, Pulido JS, Keech RV. Chorioretinal colobomas in a pediatric population. Ophthalmology. 1998;105(8):1455-8. Comment in: Ophthalmology. 1999;106(4):645-6.

9. Niesen CE. Malformations of the posterior fossa: current perspectives. Semin Pediatr Neurol. 2002;9(4):320-34.

10. Coats DK, Paysse EA, Levy ML. PHACE: a neurocutaneous syndrome with important ophthalmologic implications: case report and literature review. Ophthalmology. 1999;106(9):1739-41.

11. Kumandas S, Akcakus M, Coskun A, Gumus H. Joubert syndrome: review and report of seven new cases. Eur J Neurol. 2004;11(8):505-10.

12. Klein O, Pierre-Kahn A, Boddaert N, Parisot D, Brunelle F. Dandy-Walker malformation: prenatal diagnosis and prognosis. Childs Nerv Syst. 2003;19(78): 484-9.

13. Boddaert N, Klein O, Ferguson N, Sonigo P, Parisot D, Hertz-Pannier L, et al. Intellectual prognosis of the Dandy-Walker malformation in children: the importance of vermian lobulation. Neuroradiology. 2003;45(5):320-4.

14. Reese V, , Paller AS, Esterly NB, Ferriero D, Levy ML, et al. Association of facial hemangiomas with Dandy-Walker and other posterior fossa malformations. J Pediatr 1993;122(3):379-84.

15. Balci S, Teksam O, Gedik S. Megalocornea, macrocephaly, mental and motor retardation: MMMM syndrome (Neuhauser syndrome) in two sisters with hypoplastic corpus callosum. Turk J Pediatr. 2002;44(3):274-7.

16. Pagon RA, Clarren SK, Milam DF Jr, Hendrickson AE. Autosomal recessive eye and brain anomalies: Warburg syndrome. J Pediatr. 1983;102(4):542-6.

17. Golden JA. Cell migration and cerebral cortical development. Neuropathol Appl Neurobiol. 2001;27(1):22-8.

18. Ruibal Francisco JL, Sánchez Buron P, Piñero Martinez E, Bueno Lozano G. [Turner's syndrome. Relationship between the karyotypes and malformations and associated diseases in 23 patients]. An Esp Pediatr. 1997;47(2):167-71. Spanish.

19. Kawaguchi T, Jokura H, Kusaka Y, Shirane R, Yoshimoto T. Intraoperative direct neuroendoscopic observation of the aqueduct in Dandy-Walker malformation. Acta Neurochir (Wien). 2003;145(1):63-7. 